\title{
Pharmacophore elements of the TIPP class of delta opioid receptor antagonists
}

\author{
Henry I. Mosberg, John R. Omnaas, Katarzyna Sobczyk-Kojiro, Raj Dua, Jeffrey C. Ho, \\ Wenli Ma, Paula Bush, Carol Mousigian and Andrei Lomize \\ College of Pharmacy, University of Michigan, Ann Arbor, MI 48109-1065, U.S.A.
}

Received 17 June 1994

Accepted 8 July 1994

Key words: Opioid peptides; Pharmacophore; Tetrahydroisoquinoline carboxylic acid; TIPP

\section{SUMMARY}

A series of tri- and tetrapeptides sharing the amino-terminal dipeptide unit Tyr-Tic, found in the high-affinity delta opioid receptor antagonist Tyr-Tic-Phe-Phe (TIPP), was prepared and evaluated in receptor binding assays to explore the role(s) of the phenylalanine residues in positions 3 and 4. It was found that aromaticity of residues 3 and 4 is not required for high affinity, a lipophilic side chain in either location being sufficient, as evidenced by the high delta receptor binding affinities observed for the tetrapeptide Tyr-Tic-Ala-Leu and the tripeptide Tyr-TicLeu. These results support the suggestion of Temussi et al. [Biochem. Biophys. Res. Commun., 198 (1994) 933] that the aromatic side chain of the Tic residue corresponds to the aromatic side chain found in residues 3 or 4 in other delta-selective peptide series.

\section{INTRODUCTION}

Recently, Schiller and co-workers have described a novel series of opioid peptides based upon the lead tetrapeptide Tyr-Tic-Phe-Phe (TIPP), where Tic is tetrahydroisoquinoline carboxylic acid [1-3]. This lead compound, analogs maintaining the amino-terminal tripeptide sequence, and the tripeptide itself display high affinity for the delta type of opioid receptor. They are the most selective ligands yet reported for this receptor and are potent antagonists in delta receptor-mediated bioassays. Unlike other opioid peptides, in the TIPP series high affinity for delta receptors re- quires L-stereochemistry of the second residue, the conformationally constrained phenylalanine ana$\log$ Tic. It is widely accepted that the phenylalanine (or related aromatic) side chain occurring in residue 3 (dermorphins and deltorphins and their analogs) or residue 4 (enkephalins and ana$\operatorname{logs}$ ) is a key pharma-cophore element for opioid receptor recognition and, based upon the high affinity exhibited by the Tyr-Tic-Phe moiety, Schiller and co-workers have also proposed that the Tyr-Tic-Phe tripeptide of the TIPP peptides constitutes the delta opioid receptor message [1]. In a recent report, Temussi et al. [4] cast doubt on this premise by demonstrating that the dipep- 
tides Tyr-Tic-OH and Tyr-Tic- $\mathrm{NH}_{2}$ are themselves delta-selective antagonists. The authors propose that the aromatic ring of the Tic residue serves the function of the second aromatic group of the opioid message (in addition to $\mathrm{Tyr}^{1}$ ) and report that low-energy conformers of Tyr-Tic- $\mathrm{NH}_{2}$ can be superimposed with the rigid alkaloid naltrindole (NTI), a potent delta-selective antagonist developed by Portoghese and colleagues [5]. Although the conclusions of Temussi et al. are not unreasonable, the relatively low binding affinity and weak antagonist potency of the TyrTic dipeptides (2-3 orders of magnitude lower than reported values for TIPP [1] and NTI [5]) causes some concern. Since this affinity reduction corresponds to $\sim 3-4 \mathrm{kcal} /$ mole of binding energy, an additional specific interaction between the aromatic side chain of the $\mathrm{Phe}^{3}$ residue of TIPP and the delta opioid receptor might be necessary to realize a high-affinity interaction. We report here that, in fact, aromaticity is not required for residue 3 in TIPP, a lipophilic residue in either this position or in position 4 being sufficient to provide high delta receptor binding affinity. Our results suggest, in agreement with the proposal of Temussi et al., that it is the aromatic Tic side chain in TIPP and its analogs which corresponds to the phenylalanine residue found in other classes of opioid peptides and that the $\mathrm{Phe}^{3}$ residue of TIPP provides additional binding energy via its lipophilic character.

\section{METHODS}

Peptides 1, 3, and 4 of Table 1 were synthesized by previously described [6] standard solidphase procedures using chloromethylated polystyrene (Merrifield) resin, cross-linked with $1 \%$ divinylbenzene. Trifluoroacetic acid (TFA) was employed for deprotection, and dicyclo-hexylcarbodiimide (DCC) and 1-hydroxybenzo-triazole $(\mathrm{HOBt})$ were used as coupling agents. The $t$ butyloxycarbonyl (Boc) group was used for the protection of $\alpha$-amino functions. Deprotection and cleavage from the resin were accomplished by treatment with anhydrous hydrogen fluoride in the presence of $5 \%$ cresol and $5 \%$ p-thiocresol, with stirring for $45 \mathrm{~min}$ at $0{ }^{\circ} \mathrm{C}$. $\mathrm{HF}$ was subsequently removed by vacuum. Following extraction with 9:1 DMF:80\% HOAc and dilution with $0.1 \%$ TFA in water, the resulting peptides were purified by reversed phase high performance liquid chromatography (RP-HPLC) on a Vydac 218TP C-18 column $(2.5 \times 22 \mathrm{~cm})$ using the solvent system $0.1 \%(\mathrm{w} / \mathrm{v}) \mathrm{TFA}$ in water $/ 0.1 \%(\mathrm{w} / \mathrm{v})$ TFA in acetonitrile, by a gradient of $10-50 \%$ organic component in $40 \mathrm{~min}$ at a flow rate of 10 $\mathrm{ml} / \mathrm{min}$, and were subsequently lyophilized. The remaining peptides were synthesized employing 9 fluorenylmethyloxycarbonyl (Fmoc) protection of the amino functions, with deprotection by piperidine and coupling mediated by 2 -( $1 H$-benzotriazol-1-yl)-1,1,3,3-tetramethyluronium hexafluorophosphate (HBTU). These syntheses utilized hydroxymethylphenoxymethyl (HMP) resins from which the peptides were cleaved using a $95 \%$ solution of TFA in $\mathrm{CH}_{2} \mathrm{Cl}_{2}$. The resulting peptides were purified by RP-HPLC as described above.

Final peptide purity was determined by analytical RP-HPLC on a Vydac 218TP C-18 column $(4.6 \times 250 \mathrm{~mm})$ by a gradient of $0-70 \%$ organic component over $70 \mathrm{~min}$, with a flow rate of 1 $\mathrm{ml} / \mathrm{min}$. All analytical RP-HPLC gradients were run using the solvent system $0.1 \%(\mathrm{w} / \mathrm{v})$ TFA in water $/ 0.1 \%(\mathrm{w} / \mathrm{v})$ TFA in acetonitrile. Peaks were monitored at 220, 230, 254 and $280 \mathrm{~nm}$ and analyzed with Waters Maxima 820 software. Peaks which also appeared in chromatograms in which no peptide was injected were considered to be artifacts and were ignored. Peptide purity was then evaluated by integration of peaks and was found to be $>97 \%$ for each of the peptides reported here. Retention times ( $\mathrm{min}$ ) of the peptides under the conditions described above were: 1: $40.3 ; 2: 34.6 ; 3: 32.8 ; 4: 35.8 ; 5: 32.5 ; 6: 23.0$; and $7: 36.4$. Final product confirmation was obtained by fast atom bombardment-mass spectrometry (FAB-MS). In all cases, the anticipated molecular weights were confirmed by FAB-MS.

Opioid receptor binding assays of test ligands 
TABLE 1

BINDING AFFINITIES AND SELECTIVITIES OF TYR-TIC PEPTIDES

\begin{tabular}{lllrr}
\hline & Peptide & \multicolumn{2}{l}{$\mathrm{K}_{\mathrm{i}}(\mathrm{nM})$} & \\
\cline { 3 - 4 } & & $\left.{ }^{3} \mathrm{H}\right]$-DAMGO & $\mathrm{K}_{\mathrm{i}}(\mu) / \mathrm{K}_{\mathrm{i}}(\boldsymbol{\delta})$ \\
\hline $\mathbf{1}$ & Tyr-Tic-Phe-Phe-OH & $>10000$ & $2.75 \pm 0.22$ & \\
$\mathbf{2}$ & Tyr-Tic-Phe-OH & $>10000$ & $8.90 \pm 1.34$ & $>3640$ \\
$\mathbf{3}$ & Tyr-Tic-Phe-Ala-OH & $>10000$ & $17.7 \pm 1.95$ & $>1120$ \\
$\mathbf{4}$ & Tyr-Tic-Ala-Phe-OH & $>10000$ & $3.20 \pm 0.28$ & $>565$ \\
$\mathbf{5}$ & Tyr-Tic-Ala-Leu-OH & $>10000$ & $7.11 \pm 0.77$ & $>3130$ \\
$\mathbf{6}$ & Tyr-Tic-Ala-OH & $>10000$ & $236 \pm 41$ & $>1400$ \\
$\mathbf{7}$ & Tyr-Tic-Leu-OH & $>10000$ & $4.33 \pm 0.75$ & $>42$ \\
\hline
\end{tabular}

were performed on membrane preparations from guinea pig brain, as previously described [7]. Binding affinities were measured at $0^{\circ} \mathrm{C}$ in competition binding assays using [ $\left.{ }^{3} \mathrm{H}\right]-\mathrm{DPDPE}$ or $\left[{ }^{3} \mathrm{H}\right]-$ DAMGO as radioligands selective for delta or mu opioid receptors, respectively, and are reported as inhibition constants $\mathrm{K}_{\mathrm{i}}$. Each reported $\mathrm{K}_{\mathrm{i}}$ value and standard error of the mean (sem) is based upon at least two independent binding experiments, each done in triplicate. Binding affinities for kappa opioid receptors were also assessed, using $\left[{ }^{3} \mathrm{H}\right]-\mathrm{U} 69,593$ as the radioligand. None of the analogs displayed significant affinity for this receptor $\left(\mathrm{K}_{\mathrm{i}} \gg 10000 \mathrm{nM}\right)$.

\section{RESULTS AND DISCUSSION}

Table 1 summarizes the results of opioid receptor binding assays on a series of TIPP analogs designed to probe the importance of the phenylalanine residues in positions 3 and 4 of TIPP. As shown in Table 1 and in agreement with the results of Schiller and co-workers, TIPP (1) and TIP (2) bind with high affinity to the delta opioid receptor, as evidenced by their low $\mathrm{K}_{\mathrm{i}}$ values in competitive binding with the deltaselective radioligand $\left[{ }^{3} \mathrm{H}\right]-\mathrm{DPDPE}$. Both ligands display high selectivity for the delta receptor, neither compound exhibiting significant affinity for the mu receptor (competitive binding with the mu-selective [ $\left.{ }^{3} \mathrm{H}\right]$-DAMGO, Table 1) or the kappa receptor (data not shown). Based upon the high delta affinity of the tripeptide TIP, Schiller and co-workers have proposed that the tripeptide sequence Tyr-Tic-Phe comprises the opioid receptor message in the TIPP peptide series [1]. The results observed for 3 and 4 , in which the phenylalanine residues of TIPP are individually replaced by alanine, however, are inconsistent with this view, since the delta affinity observed for 4 , in which the $\mathrm{Phe}^{3}$ residue is replaced, is significantly higher than that for 3 , in which the $\mathrm{Phe}^{4}$ residue is replaced. While this observation casts doubt upon the importance of the aromatic nature of the $\mathrm{Phe}^{3}$ residue for delta-receptor recognition by TIP and TIPP, the possibility that, owing to the expected flexibility of these linear peptides, the $\mathrm{Phe}^{4}$ residue of 4 may be able to assume the role of the Phe ${ }^{3}$ residue of TIPP cannot be excluded. The result observed for 5 , however, argues against this possibility. This analog, which contains no aromatic residue in positions 3 or 4 , nonetheless shows similar delta-binding affinity as TIPP and its $\mathrm{Ala}^{3}$ analog 4. Apparently it is the lipophilic nature of residues 3 and 4 that is necessary for high delta affinity, indicating that neither $\mathrm{Phe}^{3}$ nor $\mathrm{Phe}^{4}$ in TIPP correspond to the second aromatic side chain (in addition to that of tyrosine) important for receptor recognition by the enkephalins, der-morphins and deltorphins. This is further suggested by the low delta affinity observed for the Ala ${ }^{3}$ tripeptide 6 compared with TIP, which binds 25 -fold more avidly. Presumably the alanyl side chain provides insufficient lipo- 
philicity for optimal interaction with the receptor. By contrast, the more lipophilic leucine side chain in 7 pro-vides additional interaction energy and results in similar binding affinity as that observed for TIP.

If, as is clear from the above, aromatic side chains are not required at residues 3 or 4 in the TIPP series of delta-selective peptides, then it follows that either the aromatic side chain of the $\mathrm{Tic}^{2}$ residue is important for receptor binding and corresponds to the phenylalanine side chain found in residue 3 or 4 in endogenous opioids and related analogs, or the TIPP peptides bind to the delta receptor in a distinctly different fashion. While the latter possibility cannot be unequivocally ruled out, the conformational comparison of Tyr-Tic- $\mathrm{NH}_{2}$ and naltrindole described by Temussi et al. and theoretical conformational analyses carried out in our laboratory, which indicate that low-energy conformations of TIPP can be readily fit to a pharmacophore model for the delta opioid receptor (Lomize, A., Pogozheva, I. and Mosberg, H.I., manuscript in preparation), argue for the former. The importance of the aromatic side chain of Tic for delta receptor recognition was deduced by Schiller and coworkers from the observation that replacement of L-Tic by L-pipecolic acid, which retains the piperidine ring of Tic but not the fused aromatic ring, leads to a drastic loss of delta-binding affinity, accompanied by a great increase in mubinding affinity [8]. The results reported here support the conclusion of Temussi et al. that this importance is founded upon the correspondance of the aromatic ring of the $\mathrm{L}-\mathrm{Tic}^{2}$ side chain with the aromatic side chain found in residues 3 or 4 in other delta-selective peptide series. The results also clearly demonstrate that, compared with the Tyr-Tic dipeptide, the additional binding energy of TIPP and related tri- and tetrapeptides derives from the lipophilic nature of the residues at position 3 or 4 , not their aromatic character.

\section{ACKNOWLEDGEMENTS}

This work was supported by the National Institute on Drug Abuse through grants DA03910 and DA00118 (Research Scientist Development Award) to H.I.M. Financial support for J.C.H. was provided by the National Institutes of Health (Training Grant GM07767) and the American Foundation for Pharmaceutical Education.

\section{REFERENCES}

1 Schiller, P.W., Nguyen, T.M.-D., Weltrowska, G., Wilkes, B.C., Marsden, B.J., Lemieux, C. and Chung, N.N., Proc. Natl. Acad. Sci. USA, 89 (1992) 11871.

2 Schiller, P.W., Weltrowska, G., Nguyen, T.M.-D., Wilkes, B.C., Chung, N.N. and Lemieux, C., J. Med. Chem., 36 (1993) 3182

3 Nevin, S.T., Toth, G., Nguyen, T.M.-D., Schiller, P.W. and Borsodi, A., Life Sci., 53 (1993) PL57.

4 Temussi, P.A., Salvadori, S., Amodeo, P., Bianchi, C., Guerrini, R., Tomatis, R., Lazarus, L.H., Picone, D. and Tancredi, T., Biochem. Biophys. Res. Commun., 198 (1994) 933.

5 Portoghese, P.S., Sultana, M. and Takemori, A.E., J. Med. Chem., 31 (1988) 281.

6 Mosberg, H.I., Omnaas, J.R., Medzihradsky, F. and Smith, C.B., Life Sci., 43 (1988) 1013.

7 Heyl, D.L. and Mosberg, H.I., J. Med. Chem., 35 (1992) 1535.

8 Schiller, P.W., Nguyen, T.M.-D., Berezowska, I., Weltrowska, G., Schmidt, R., Marsden, B.J., Wilkes, B.C., Lemieux, C. and Chung, N.N., In Yanaihara, N. (Ed.) Peptide Chemistry 1992 (Proceedings of the 2nd Japan Symposium on Peptide Chemistry), ESCOM, Leiden, 1993, pp. 337-340. 